$$
\text { SAND- }-97-8653 C
$$

\title{
Computational Models to Quantify Uncertain Emergency Search Techniques-A Comparison of Measured and Synthetic Gamma-Ray Detector Response Functions
}

\author{
Michael M. Johnson, Michael E. Goldsby, and William B. Wilcox \\ Sandia National Laboratories (SNL) \\ Livermore, California USA \\ Walter K. Hensley \\ Pacific Northwest National Laboratory (PNNL) \\ Richland, Washington USA \\ Richard G. Hansen \\ Bechtel Nevada, Remote Sensing Laboratory (RSL) \\ Las Vegas, Nevada USA
}

\begin{abstract}
As recent world events show, criminal and terrorist access to nuclear materials is a growing national concern. The national laboratories have developed quantitative models to simulate the response of detection equipment when looking for lost or stolen nuclear material. SYNTH, a code written to synthesize typical gamma-ray spectroscopy experiments, and QUEST, a model to Quantify Uncertain Emergency Search Techniques, calculate the response functions of gammaray detectors for arbitrary source types and shielding configurations. In addition, QUEST provides an interactive, threedimensional user interface supporting the virtual quest for nuclear materials, making possible quantitative comparisons of various sensor technologies and inspection methodologies. The probability of detecting a radioactive source during an inspection is a function of many different variables, including source type, structure geometry (including shielding), inspection dynamics (path and speed), detector (type, size, and resolution), and analysis algorithms.
\end{abstract}

We present the results of our study comparing the synthetic Sodium Iodide (NaI) and Germanium (Ge) detector responses generated by both SYNTH and QUEST with those generated by real detectors deployed in the field. Quantitative models, such as the ones presented here, are important since they, (1) allow inspection teams to maximize the probability of finding materials of interest, (2) aid in the development of new instruments and detection techniques, and (3) support other diverse applications including environmental monitoring, nuclear facilities inspections, and radiation safety responder training.

\section{Introduction}

There are many challenges in looking for nuclear material (Figure 1). The probability of an inspection team detecting a radioactive source is a function of many different variables. Moreover, probabilities of detection are unknown quantities-while the probability of detection is assumed to be high based on known detection ranges for an unshielded source, no quantitative estimates are available. Inspection requirements are often based on experience and intuition. Typical questions for which a quantitative analysis is necessary include developing effective inspection patterns for a given source, structure, and detector; estimating the probability of detection for a source,' structure, detector, and inspection pattern; and estimating the payoffs from new detector technologies and designs.

QUEST provides a tool to answer these questions and others like them by simulating all aspects of the inspection process ${ }^{1}$. QUEST simulates the inspection for nuclear materials and calculates detector response for various source types and locations. To accomplish this, QUEST provides the ability to call up computer models of many different building types in which a nuclear device may be concealed. These structures can
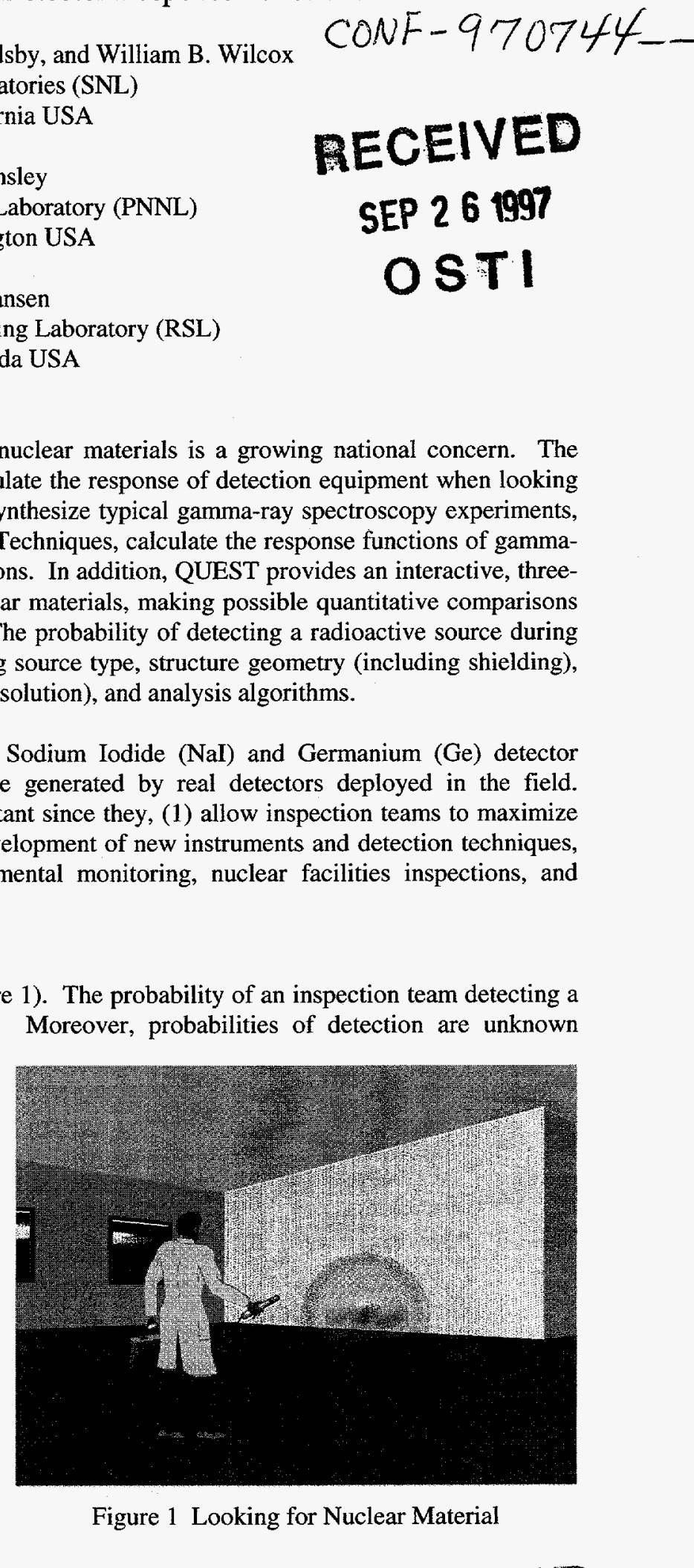

Figure 1 Looking for Nuclear Material

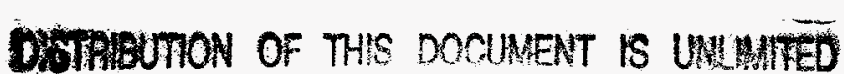

\footnotetext{
Presented at the $38^{\text {th }}$ Annual Meeting of the Institute of Nuclear Materials Management (INMM) in Phoenix, Arizona, July, 1997.
} 


\section{DISCLAIMER}

This report was prepared as an account of work sponsored by an agency of the United States Government. Neither the United States Government nor any agency thereof, nor any of their employees, makes any warranty, express or implied, or assumes any legal liability or responsibility for the accuracy, completeness, or usefulness of any information, apparatus, product, or process disclosed, or represents that its use would not infringe privately owned rights. Reference herein to any specific commercial product, process, or service by trade name, trademark, manufacturer, or otherwise does not necessarily constitute or imply its endorsement, recommendation, or favoring by the United States Government or any agency thereof. The views and opinions of authors expressed herein do not necessarily state or reflect those of the United States Government or any agency thereof. 


\section{DISCLAmIER}

Portions of this doement may be illegible in electronic image produets. Images are produced from the best available original docoment 
be developed using any one of many different Computer-Aided Design (CAD) packages. Once a structure has been developed, the user can import the building design into the QUEST simulation. The primary QUEST window displays the firstperson, three-dimensional point-of-view of the inspector (Figure 2). The user opens a secondary window to show the twodimensional floor plan. The user then specifies the characteristics of the nuclear material source (for example, a nuclear weapon or radiation dispersal device) within the floor plan and selects a detector model (such as a hand-held radiation sensor). Once the simulation begins, the user can move throughout the simulated environment, analyzing the calculated detector response. In general, QUEST supports a wide range of applications such as environmental monitoring, nuclear facilities inspections, and radiation safety responder training.

SYNTH, developed at PNNL, is an interactive Microsoft

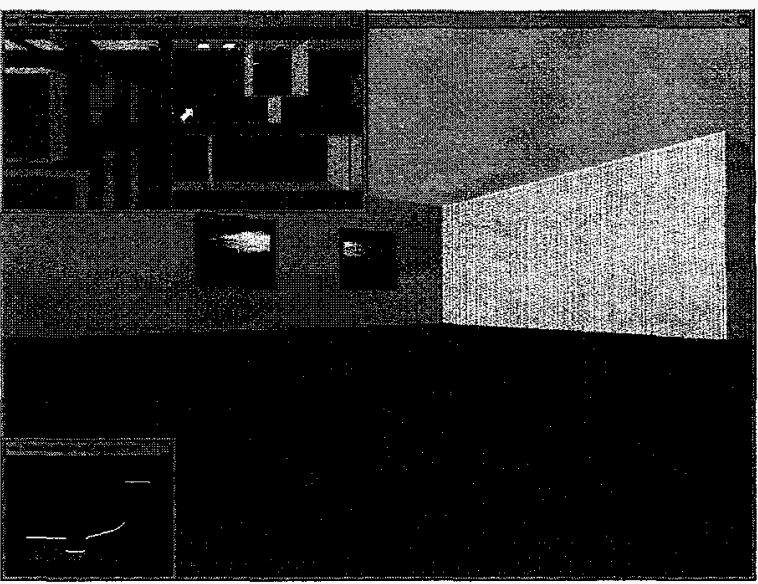

Figure 2 Structure Inspection Showing Ray Shot

Windows ${ }^{\mathrm{TM}}$ based program designed to synthesize the results of typical gamma-ray spectroscopy experiments / measurements ${ }^{2}$. Most gamma-ray spectroscopy experiments / measurements involve individual components that each have a predictable behavior (the radiation source, absorbers, detectors, and electronics). Gamma-ray spectroscopists usually take these into account in the design, and when reducing the data acquired from an experiment or measurement. SYNTH allows a user to specify the physical characteristics of a gamma-ray source (size, bulk composition, and the type and quantity of radionuclides producing the radiation), the source-to-detector distance and the type and thickness of absorbers, the size and composition of the detector ( $\mathrm{Ge}$ or $\mathrm{NaI})$, and the electronic setup used to gather the data.

SYNTH can generate a complex gamma-ray spectrum with hundreds of peaks in only a few minutes because the computational models are based on hard-coded algorithms (rather than Monte Carlo techniques). The result is a spectrum which includes accurate full energy peaks, Compton edges, single and double escape peaks, statistical fluctuations, and appropriate Peak-to-Compton ratios. Options exist to include statistical fluctuations, add (and normalize) a previously stored spectrum (real or synthetic), and save the generated spectrum to disk. A group of display options also allows detailed examination of the output spectrum and comparison with a reference spectrum. Both SYNTH and QUEST include an augmented, electronic version of the standard Erdtmann-Soyka gamma-ray database ${ }^{3}$.

It is necessary to validate QUEST against laboratory and field tests to allow users to have confidence in its results. Validation can also be attained by comparing QUEST to other codes, such as SYNTH, that are regarded as standards. We present the results of two series of validation tests. In the first, spectra generated by QUEST were compared to spectra collected in the laboratory at PNNL and to spectra generated by the SYNTH program. In the second, detector algorithm output generated by QUEST was compared to output of the same algorithms run against data collected under field conditions at the Remote Sensing Laboratory in Las Vegas. Comparison of the results is favorable in both cases.

\begin{tabular}{|c|c|c|c|}
\hline & $\mathrm{HEU} / \mathrm{Ge}$ & Pu/Go & Pu/Nal \\
\hline \multicolumn{4}{|l|}{ Detector } \\
\hline End Cap Thick. $(\mathrm{mm})$ & 0.51 & 0.51 & 0.51 \\
\hline Material & Al & Al & Al \\
\hline Deadlayer Thick. $(\mathrm{mm})$ & 1.0 & 1.0 & $\mathrm{n} / \mathrm{a}$ \\
\hline Diameter $(\mathrm{cm})$ & 6.0 & 6.1 & 12.7 \\
\hline Length $(\mathrm{cm})$ & 7.0 & 4.4 & 5.08 \\
\hline Efficiency $(\%)$ & 40.0 & 30.04 & $n / a$ \\
\hline Resolution & $1.8 \mathrm{keV}$ & $2.1 \mathrm{keV}$ & $7.2 \%$ \\
\hline \multicolumn{4}{|l|}{ Electronics } \\
\hline Zero (keV) & 0.0 & 0.0 & 0.0 \\
\hline Gain (keV/ch) & 0.34 & 0.243 & 0.39 \\
\hline Linearity $\left(\mathrm{keV} / \mathrm{ch}^{2}\right)$ & 0.0 & 0.0 & 0.0 \\
\hline Channets & 8192 & 4096 & 4096 \\
\hline Count Time (sec.) & $34,669.08$ & 1000 & 600 \\
\hline \multicolumn{4}{|l|}{ Sample Properties } \\
\hline Area $\left(\mathrm{cm}^{2}\right)$ & 1.0 & 17.18 & 17.18 \\
\hline Thickness $(\mathrm{cm})$ & 0.2 & 0.5 & 0.5 \\
\hline Mass $(\mathrm{gm})$ & 1.5 & 98.4 & 98.4 \\
\hline Distance $(\mathrm{cm})$ & 5.08 & 54.61 & 210.82 \\
\hline Bulk Matrix & $100 \%$ Uranium & $88 \% \mathrm{Pu} / 12 \% \mathrm{O}$ & $88 \% \mathrm{Pu} / 12 \% \mathrm{O}$ \\
\hline Absorber (cm) & $n / a$ & $0.6 \mathrm{Fe}$ & $0.6 \mathrm{Fe}$ \\
\hline Source Terms (gm) & $\begin{array}{l}{ }^{235} \cup 1.40 \theta+00 \\
{ }^{238} \cup 1.00 e-01 \\
{ }^{232} \cup 2.00 e-10\end{array}$ & $\begin{array}{l}{ }^{238} \mathrm{Pu} 2.0660-02 \\
{ }^{239} \mathrm{Pu} 9.249 \mathrm{e}+01 \\
{ }^{240} \mathrm{Pu} 5.6000+00 \\
{ }^{241} \mathrm{Pu} 2.647 \mathrm{e}-01 \\
{ }^{242} \mathrm{Pu} 2.066 \theta-02 \\
{ }^{241} \mathrm{Am} 5.5100-02\end{array}$ & $\begin{array}{l}{ }^{238} \mathrm{Pu} 2.066 e-02 \\
{ }^{239} \mathrm{Pu} 9.249 \theta+01 \\
{ }^{240} \mathrm{Pu} 5.600 \theta+00 \\
{ }^{24 i} \mathrm{Pu} 2.6479-01 \\
{ }^{242} \mathrm{Pu} 2.066 \theta-02 \\
{ }^{241} \mathrm{Am} 5.540-002\end{array}$ \\
\hline Decay Time & 20 years & 19.18 years & 19.18 years \\
\hline
\end{tabular}

Table 1 Spectral Comparison Configurations 


\section{Comparison of Spectra}

Spectral data were collected at PNNL and compared to spectra generated by QUEST runs that simulated the laboratory conditions. The QUEST spectra were also compared to spectra generated by the SYNTH software.

The data acquisition system used to collect the laboratory spectra was very simple, and used off-the-shelf Nuclear Instrument Modules (NIM), and commercially available software. A standard NIM bin was used to house a HVbias supply [for the PMT], a spectroscopy grade linear amplifier, and an ORTEC ADCAM Multi-Channel Analyzer [MCA]. The ADCAM module was interfaced to a laptop computer which ran an MCA emulator program to control the acquisition, and record the accumulated spectra.

The laboratory records that provide traceability of the sources used in the laboratory were used to specify the quantity of the isotopes on the certification date of the standard, and QUEST and SYNTH decayed the source to date of measurement. The detector manufacturers' quality assurance data sheets were used to specify the sodium iodide and germanium diode parameters. The absorbers specified were air, the detector end cap material, the iron casing surrounding the plutonium oxide source, and in the case of the germanium detectors the germanium dead layer. The source-to-detector distance and the sample time were specified, as were the system electronics settings for gain and zero. In the following examples, as parameterized in Table 1, the Compton continuum

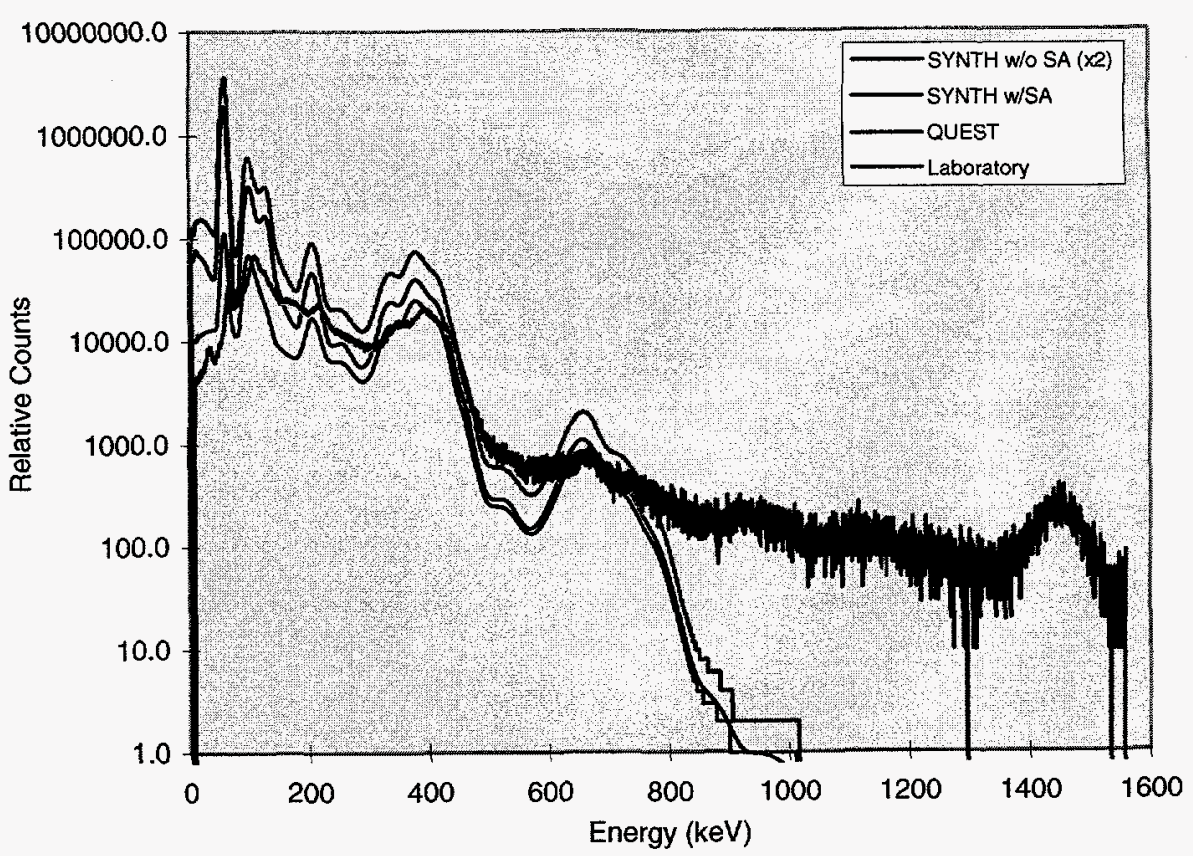

Figure 3 Comparison of Pu / Nal Laboratory, Synthetic SYNTH and QUEST Spectra

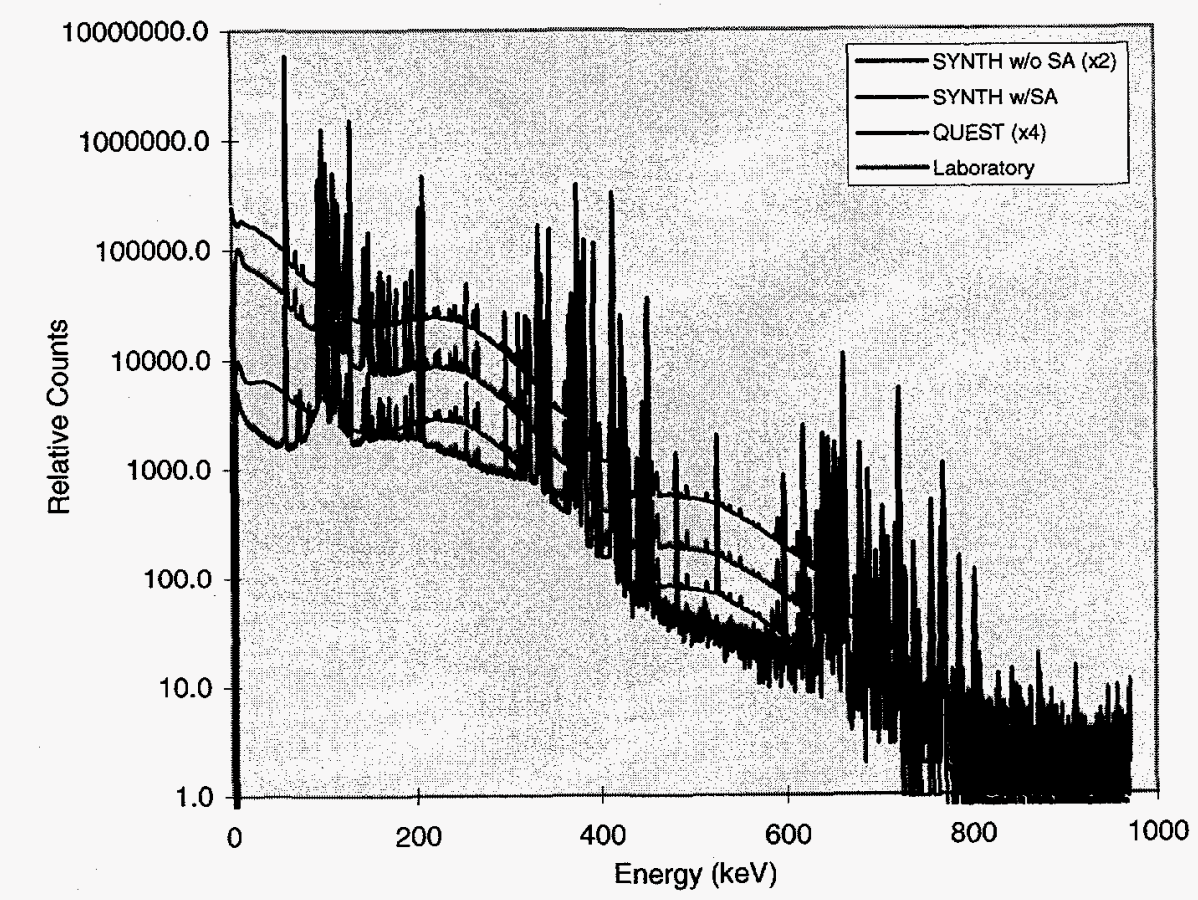

Figure 4 Comparison of Pu / Ge Laboratory, Synthetic SYNTH and QUEST Spectra 
was remarkably free of deviation down to $500 \mathrm{keV}$, below which QUEST underestimated the experimental value. This underestimation is attributed to, (1) selfattenuation of the source, and (2) gamma-ray scattering in the lead shield of the detector, effects that are not currently simulated by QUEST's physics model.

In Figure 3, QUEST and SYNTH were both setup to model the response of a 5"x2" $\mathrm{NaI}(\mathrm{Tl})$ detector to approximately 100 grams of a 20-year-old plutonium oxide source. As the laboratory spectrum was

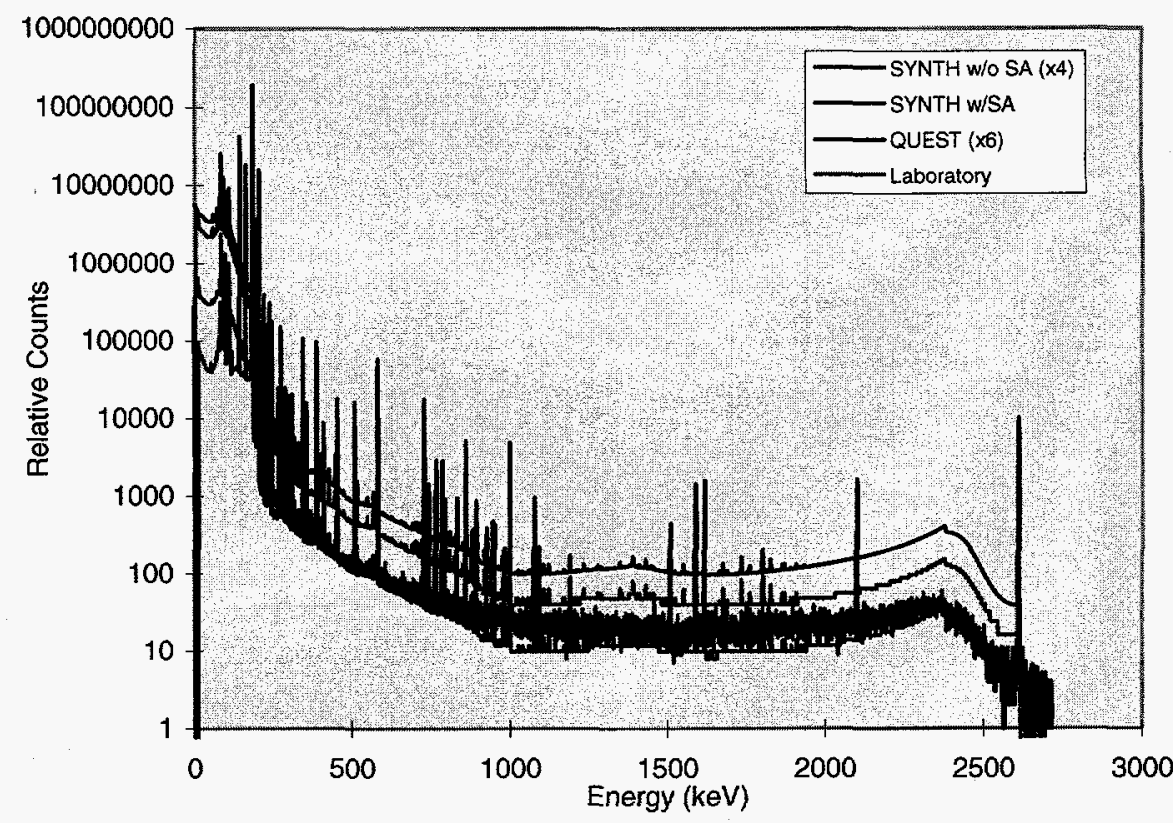

Figure 5 Comparison of HEU / Ge Laboratory, SYNTH and QUEST Synthetic Spectra acquired with an unshielded detector assembly, it is composed of the signal from the Pu source as well as a significant contribution from the ambient background. In fact, almost all of the counts above $800 \mathrm{keV}$ can be accounted for by the ${ }^{208} \mathrm{Tl}$ (a decay product of ${ }^{232} \mathrm{Th}$ ), and ${ }^{40} \mathrm{~K}$ that occur naturally in the soil and in concrete.

Below $800 \mathrm{keV}$, the shape of the laboratory spectrum is dominated by the signal from the Pu source and the Compton continuum from the high energy components of the ambient background. Although the energy calibrations were not fine tuned, both QUEST and SYNTH do reasonably well above $150 \mathrm{keV}$. Below that value, the differences between the two codes become more apparent. SYNTH generated spectra with and without self-attenuation are shown; SYNTH appears to overcorrect somewhat for self-attenuation effects in the sample. The QUEST code, on the other hand, uses the simpler point-source model (which makes no self-attenuation correction) and thus over predicts the activity of lower energy photons. In each spectra figure, legend indicated data series multipliers have been applied to ease comparison.

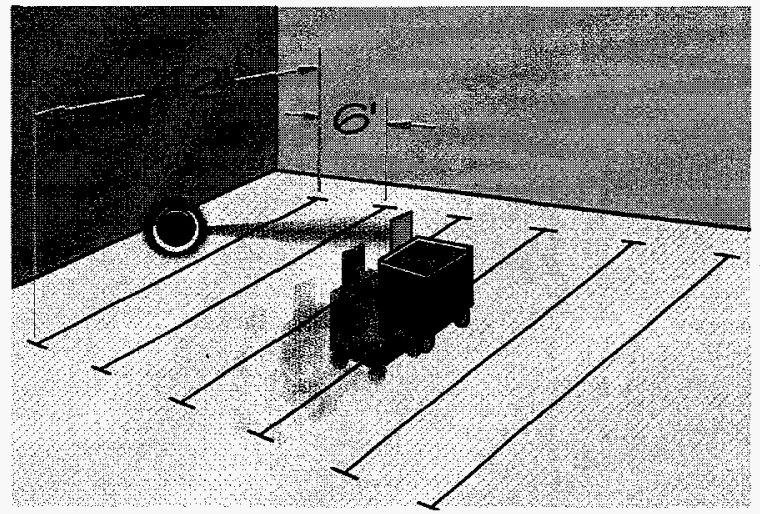

Figure 6 Laboratory Algorithm Response Setup

The same general characteristics may be seen in the plutonium spectra that were acquired with Ge detectors, shown in Figure 4. Other than the obvious difference in detector resolution, the laboratory Ge spectrum has a better signal-to-background ratio (the

\begin{tabular}{|c|c|c|}
\hline Detector & $\begin{array}{c}\text { Bicron Nal } \\
3 \mathrm{M} 3 / 3\end{array}$ & $\begin{array}{l}\text { Harshaw Nal } \\
20 \mathrm{MB} / 57-\mathrm{x} 4\end{array}$ \\
\hline End Cap Thick. $(\mathrm{mm})$ & 0.5 & 0.5 \\
\hline Material & Al & A \\
\hline Diameter $(\mathrm{cm})$ & 7.62 & 12.7 \\
\hline Length $(\mathrm{cm})$ & 7.62 & 5.08 \\
\hline Resolution & $7.4 \%$ & $9.8 \%$ \\
\hline \multicolumn{3}{|l|}{ Electronics } \\
\hline Zero (keV) & 0.0 & 0.0 \\
\hline Gain (keV/ch) & 3.0 & 3.0 \\
\hline Linearity $\left(\mathrm{keV} / \mathrm{ch}^{2}\right.$ ) & 0.0 & 0.0 \\
\hline Channels & 1024 & 1024 \\
\hline Count Time (sec.) & 1.0 & 1.0 \\
\hline \multicolumn{3}{|l|}{ Sample Properties } \\
\hline Absorber (cm) & $\mathrm{n} / \mathrm{a}$ & $3.81 \mathrm{~Pb}, 0.32 \mathrm{Fe}$ \\
\hline Source Terms (gm) & $\begin{array}{c}{ }^{238} \mathrm{Pu} 2.10 \mathrm{e}-04 \\
{ }^{239} \mathrm{Pu} 9.395-\theta 01 \\
{ }^{240} \mathrm{Pu} 5.688 \mathrm{e}-02 \\
{ }^{241} \mathrm{Pu} 2.690 e-03 \\
{ }^{242} \mathrm{Pu} 2.10 e-04 \\
{ }^{241} \mathrm{Am} 5.60 \mathrm{e}-04\end{array}$ & $\begin{array}{c}{ }^{60} \mathrm{Co} 2.41 \mathrm{e}-03 \\
\mathrm{mCi}\end{array}$ \\
\hline Decay Time & 26 years & n'a \\
\hline
\end{tabular}

Table 2 Algorithm Comparison Configurations 
$\mathrm{Ge}$ detector was smaller and less efficient, so the source-to-detector distance was much smaller), and the energy calibration (keV/channel) is different by almost a factor of two.

In a separate experiment, a small quantity of Highly Enriched Uranium (HEU) was counted in the laboratory, and subsequently modeled by the SYNTH, and QUEST codes. The resulting spectra, shown in Figure 5, are dominated by the characteristic "signature" of ${ }^{235} \mathrm{U}$ (and its daughters) below $250 \mathrm{keV}$. Above that energy, the bulk of the activity is due to trace amounts $(0.1 \mathrm{ppb})$ of ${ }^{232} \mathrm{U}$ in the material.

\section{Comparison of}

\section{Algorithm Responses}

Data collection was done at RSL using standard radiological sources and off-the-shelf NaI gamma-ray detectors (Table 2). Detector output was collected during a "walk-by" inspection for a specific

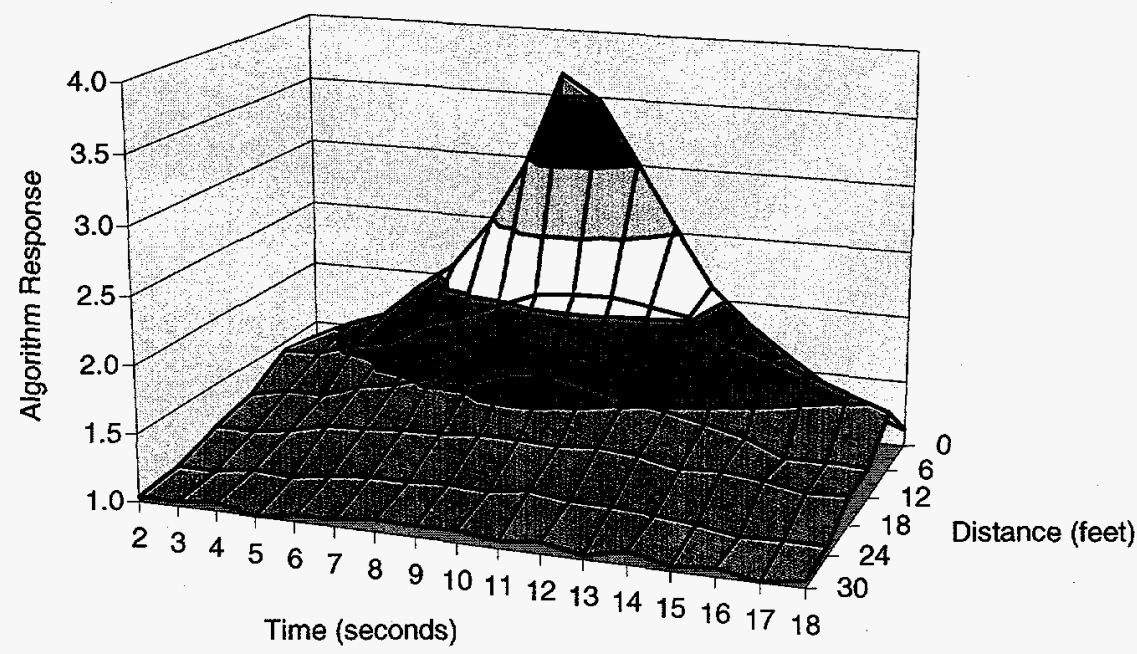
laboratory configuration (Figure 6). The data was fed to the QUEST detection algorithms and the algorithm output recorded. The data from the detectors was recorded at approximate one-second intervals, and consecutive samples were summed as necessary to simulate specific algorithms. Each inspection configuration was also simulated in QUEST using synthetic sources, detectors and paths, and the algorithm output was recorded and compared to that developed from the RSL data.

The laboratory data acquisition system and software employed were originally developed by EG\&G/Energy Measurements. Commercial off-the-shelf pre-amplifiers and amplifiers were utilized. The MCA employed for data acquisition was the EG\&G ORTEC Model 920 Spectrum Master MCA. This MCA can acquire 1024-channel spectra from up to 16 detectors simultaneously. Each detector had its amplified output fed to separate input on the Model 920. Running multiple detectors into a single Model 920 had the advantage of reducing the number of separate MCAs required, but it did have a disadvantage of increasing the dead time. Real time is the actual wall clock time. Live time is the time during which the MCA is not busy processing a pulse and, hence, is available to accept a new pulse. Dead time is the difference

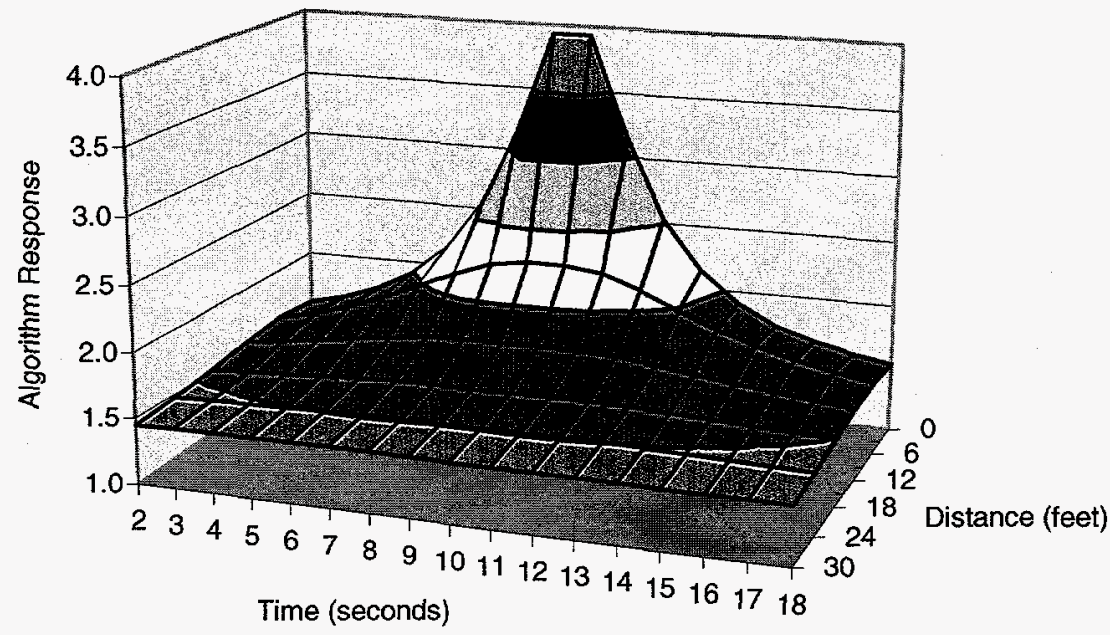
between the real and live times, expressed as a percentage of the real time. Although individual

Figure 8 QUEST ${ }^{60} \mathrm{Co}$ Algorithm Response 
spectra were taken for each detector, the dead time for each spectrum was the total MCA dead time (the sum of the dead time from all of the detectors connected to the 920), not just the dead time of that single detector. QUEST makes no provision for dead time in the sampling interval, so it was necessary to apply a correction factor to the algorithm inputs equal to the ratio of live time to real time.

In collecting the laboratory data, six paths were used following parallel lines approximately forty-two feet in length and six feet apart. The sources used were an unshielded, $2 \mathrm{~cm}$ diameter disk of ${ }^{239} \mathrm{Pu}$, and a shielded ${ }^{60} \mathrm{Co}$ sample. Two different QUEST algorithms were used to evaluate the collected spectra: gross count and a windowed algorithm. The former computes the logarithm to the base two of the sum of the counts over all detector channels. The latter computes the logarithm to the base two of the difference between the counts in a window $A(45 \mathrm{keV}$ to $450 \mathrm{keV}$ ) and a window $B$ ( $450 \mathrm{keV}$ to $3 \mathrm{MeV}$ ) scaled by a factor $k . k$ represents the ratio of the background counts in $A$ and $B$ for a reference background collected using the same detector. The output of both algorithms was normalized to zero.

Figures 7 and 8 show the algorithm output for the laboratory data and QUEST for the ${ }^{60}$ Co sample and gross count algorithm. Here, the sampling period was one second, and the experimenter pushed the detector cart from left to right in front of the source. The graphs show in three-dimensions the relationship between inspector location (offset distance from the source in feet), position in time along the path (given in seconds), and the resulting algorithm response. Figure 9 shows a comparison of ${ }^{239} \mathrm{Pu}$ laboratory and QUEST windowed algorithm response. Here, only response values collected at offsets of six, twelve, and eighteen feet from the source are given. The sampling period was two seconds. The asymmetric shape of the laboratory data was a result of the shielding effects of the laboratory cart equipment layout and presence of the experimenter's body alongside the cart. In each of the these experiments, QUEST slightly overestimates the algorithm response since it does not account for self-attenuation in the source.

\section{Conclusions}

The presented experiments demonstrate the ability of both SYNTH and QUEST to synthesize static source behavior and detector response. In addition, employing user configurable detection algorithms, QUEST gives realistic output from real-time, three-dimensional simulations. Using these capabilities, QUEST provides a means of calculating the probability of nuclear material detection within a given scenario. Computational models such as SYNTH and QUEST may be successfully employed to quantify uncertain emergency search techniques.

\section{Acknowledgements}

This work was sponsored by the United States Department of Energy under Contracts DE-AC0494AL85000, DE-AC06-76RLO 1830, and DE-AC08-96NV11718.

\section{References}

1 Johnson, M., Goldsby, M., Plantenga, T., Wilcox, W., and Hensley, W., "A Model to Quantify Uncertain Emergency Search Techniques, Theory and Application", Proceedings of the $37^{\text {th }}$ Annual Meeting of the INMM, August 1996.

2 Hensley, W., McKinnon, A., Miley, H., Panisko, M., and Savard, R., "SYNTH: A Spectrum Synthesizer," Proceedings of the 35th Annual Meeting of the INMM, pg. 629, 1994.

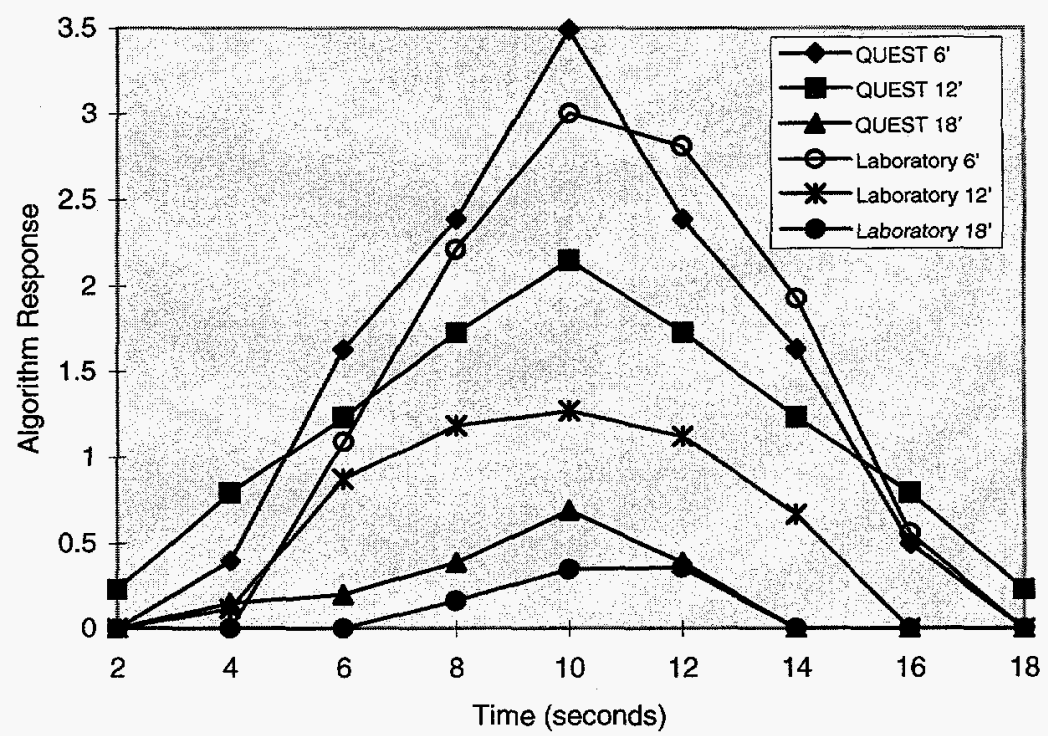

Figure 9 Comparison of ${ }^{239} \mathrm{Pu}$ Laboratory and QUEST Algorithm Response

3 Erdtmann, G., and Soyka, W., The Gamma Rays of the Radionuclides, New York, Verlag Chemie, 1979. 